\title{
The effects of economic status and recent experience on innovative behavior under environmental variability: An experimental approach
}

\author{
Frank J. van Rijnsoever ${ }^{\mathrm{a}, *}$, Marius T.H. Meeus ${ }^{\mathrm{b}, 1}$, A. Rogier T. Donders ${ }^{\mathrm{c}, 2}$ \\ a Utrecht University, Innovation Studies, Copernicus Institute of Sustainable Development, Heidelberglaan 2, 3584 CS Utrecht, The Netherlands \\ b Tilburg University, Center for Innovation Research, Department of Organization Studies, P.O. Box 90153, 5000 LE Tilburg, The Netherlands

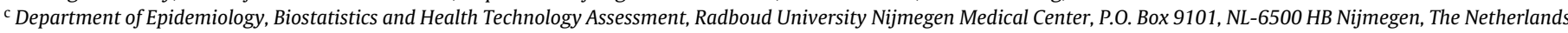

\section{A R T I C L E I N F O}

\section{Article history:}

Received 16 May 2011

Received in revised form 16 January 2012

Accepted 14 February 2012

Available online 7 March 2012

\section{Keywords:}

Experiment

Innovation

Risk-taking

Status

Recent experience

Environmental change

Discrete choice experiment

\begin{abstract}
A B S T R A C T
We build and empirically test a model that predicts the display of innovative behavior as a function of environmental change, with recent experience and economic status acting as moderators. We start with the model developed by Slevin (1971), which evolved from the so-called innovation boundary. This is the threshold beyond which the display of innovative behavior becomes attractive. We show how environmental change creates uncertainty about the position of the innovation boundary; however, this uncertainty is reduced by recent experiences. Furthermore, economic status serves as both an enhancer and an inhibitor of innovation. Our model was tested and largely confirmed in two experiments: one conducted in a laboratory setting and one conducted as a discrete choice experiment. Currently experiments are rarely conducted in the field of innovation studies. By presenting this evidence we also hope to encourage more authors to conduct experiments in their work.
\end{abstract}

(c) 2012 Elsevier B.V. All rights reserved.

\section{Introduction}

During the last two decades much research has been dedicated to explaining the innovative behavior of various types of agents, such as individuals (Midgley and Dowling, 1993; Rogers, 2003; Van Rijnsoever and Donders, 2009), organizations (Bolton, 1993; Damanpour and Gopalakrishnan, 1998; Meeus and Oerlemans, 2000) and even animals (Laland and Reader, 1999; Reader and Laland, 2003).

Important drivers of innovative behavior on the organizational level that have been identified are environmental change (Damanpour and Gopalakrishnan, 1998; Hannan and Freeman, 1989; Scott, 1995), past behavior (Greve, 1998, 2003), and firm characteristics such as slack resources (Cheng and Kesner, 1997; Cyert and March, 1963; Hannan and Freeman, 1984), or comparisons with organizational reference groups (Massini et al., 2005; Scott, 1995). Similar drivers have been found at the individual level (Cancian, 1967; Rogers, 2003; Van Rijnsoever and Oppewal, 2012), and in animal behavior (Reader and Laland, 2003).

\footnotetext{
* Corresponding author. Tel.: +31 30253 7484; fax: +31302532746. E-mail addresses: F.J.vanrijnsoever@uu.nl (F.J. van Rijnsoever), M.T.H.Meeus@uvt.nl (M.T.H. Meeus), R.Donders@epib.umcn.nl (A.R.T. Donders).

1 Tel.: +31134668344

2 Tel.: +31243617794.
}

Recently, Sørensen et al. (2010) rightly stated that the role that has been given to experiments in innovation research is too small, and that experiments can complement existing research methods. For example, studies on the organizational level are often based on the results of surveys. They are typically uncontrolled, have a low internal validity and do not allow for making causal inferences (Bryman, 2008). The complex interactions between innovating organizations and their environments hardly allow for controlled experimental conditions. Given the limitations in research design on the organizational level, researchers are forced to resort to the individual level for formal experimental empirical evidence. Conducting controlled experiments and triangulating them with other studies (Colquitt, 2008) can provide many contemporary findings with an internally valid empirical foundation (Campbell and Stanley, 1966).

An advocate for explaining innovative behavior in controlled experimental conditions is Slevin (1971) who has empirically shown that the current level of success and level of aspiration yield a predictable discrimination between individuals who try new strategies and those who stick to the existing strategies.

The performance of agents is closely linked to the pressures and opportunities regulated by environmental variability (Boyd and Richerson, 1985; Hannan and Freeman, 1989; Scott, 1995). Pressures and opportunities motivate agents either to repeat a current behavior or to switch to a novel behavior. However, the 
model proposed by Slevin does not take into account environmental variability. Therefore, in this paper we attempt to expand Slevin's model (1971) to explain innovative behavior under controlled experimental conditions by asking the following research question: "To what extent does environmental change influence the relationship between recent experience, economic status and innovative behavior?"

In order to develop a background for our model, we review the literature that attempts to explain the influence that environmental change, recent experience and economic status can have on the innovative behavior of individuals and organizations. These theoretical factors, together with insights from the corresponding strands of literature, are combined into a single theoretical model from which we derive our main hypothesis. Further, we respond to the call of Sørensen et al. (2010) by providing two studies on innovative behavior based on the experimental research method. We present the results of a controlled experimental behavioral study and a discrete choice experiment (DCE) that largely confirm our theoretical reasoning. Subsequently, we provide a conclusion and discussion.

\section{Theoretical background}

\subsection{Conceptualizing innovative behavior}

Innovation has been conceptualized in many different manners and contexts (see Rosenkopf and McGrath, 2011), which has led to a variety of definitions for what innovative behavior exactly is. Common elements identified are novelty and risk. In this study we focus specifically on the display of innovative behavior.

A first issue in defining innovative behavior is for whom the innovation is new. Authors like Pavitt (1984) and Reader and Laland (2003) have chosen to see innovation as something that is new to the entire population. Others, like Edquist (1997) and Tidd et al. (2001), choose to say nothing about the level of perceived newness. Rogers (2003), who looks at the adoption and diffusion of innovations, and also Slevin (1971), define innovation as being new to the individual agent. Since we expand upon his model, we follow Slevin (1971) and view innovation as new to the individual agent. We adopt his definition and define innovative behavior as a form of behavior that occurs when an individual (or agent) tries something new.

To grasp the concept better, we need to make a distinction between routines, skills and innovation. The term 'skills' is reserved for the individual level, while the term 'routines' is applied on the organizational level; a routine always involves multiple agents (Becker, 2004; Cohen and Bacdayan, 1994). A routine is a "regular and predictable behavioral pattern displayed" (Nelson and Winter, 1982 , p. 14), while a skill is "a capability for a smooth sequence of coordinated behavior that is ordinarily effective relative to its objectives, given the context in which it normally occurs" (Nelson and Winter, 1982, p. 73). The development of both routines and skills has different advantages. For example, they make our actions more reliable, increase efficiency and reduce uncertainty (Becker, 2004). On the other hand, their context specificity decreases behavioral flexibility and therefore can be a serious obstacle to more radical change (Becker, 2004; Broder and Schiffer, 2006). Skills and routines are related to each other in such a manner that routines can be viewed as the sum of interacting skills from different individuals. Zollo and Winter (2002) call such regular activities operational routines, while March (1991) sees these activities as exploitation.

Innovative behavior can be viewed as a novel action that forms a departure from practicing operational routines or skills (Nelson and Winter, 1982). However, when innovative behavior is repeated successfully a number of times, it can eventually evolve into an operational routine or a skill (Becker, 2004; Cohen and Bacdayan, 1994; Nelson and Winter, 1982) for organizations (Ackerman, 1988; Betsch et al., 2001; Broder and Schiffer, 2006) for individuals. Two stages can thus be recognized in the display of innovative behavior. The first stage is the novel response, which is the first time the behavior is displayed. The second stage is the continuation of this behavior, which is the development of operational routines or skills. In this stage, the agent still experiments with alternative approaches and searches for optimal solutions, but new knowledge is required in this process (Benner and Tushman, 2002). Therefore the novel response stage can be seen as part of what March (1991) calls exploration, while the routinization stage can be seen as an exploitation activity. In this research, we focus only on exploration of the novel response and the primary stages of routinization directly after that, but not on exploitation of operational routines.

Since innovative behavior is perceived to be new, it implies a higher amount of uncertainty. It is therefore, by definition, more risky than continuing existing routines or skills (Becker, 2004; Benner and Tushman, 2002; Greve, 1998; Rogers, 1995). This element of risk-taking is a key feature of innovative behavior and explains the likelihood of displaying the behavior (Bloom and Milkovich, 1998; Giacquinta, 1975; Rosenkopf and McGrath, 2011). The amount of risk is reduced when the behavior is repeated more often since the agent can increasingly benefit from the advantages of routinization.

\subsection{Environmental change and innovative behavior}

In the context of innovation an agent's environment is often conceptualized to consist of other agents on which the agents depends (Pfeffer and Salancik, 2003), and institutions (e.g. the rules of the game; North, 2005; Scott, 1995) that affect the agent. These elements of the environment change over time. The evolutionary argument to explain innovative behavior is that such environmental change invokes an adaptive response (Boyd and Richerson, 1985; Cheng and Kesner, 1997; Hannan and Freeman, 1989; Nelson and Winter, 1982). The reason for this is that existing routines are often unable to cope with new elements in the environment and consequently performance may deteriorate. ${ }^{3}$ Innovative behavior is determined by the agent's ability to respond to environmental change. This ability can either take the form of ad hoc problem solving or a dynamic capability (Winter, 2003). Ad hoc problem solving is neither routine, patterned nor repetitious. A dynamic capability, on the other hand, is a "learned and stable pattern of collective activity through which the organization generates and modifies its operating routines in pursuit of improved effectiveness" (Zollo and Winter, 2002, p. 340). A dynamic capability can thus be seen as a learned ability to change operational routines, usually in response to environmental change. Ad hoc problem solving usually suffices when there is a one-time punctuated change, but in case of an environment that demands continuous adaptation of routines, dynamic capabilities are required.

Conceptually, environmental change is often depicted as having two states (Ambrosini et al., 2009; Eisenhardt and Martin, 2000; Zollo and Winter, 2002): environments are either characterized as (1) stable or changing slowly in a predictable manner or (2) as highly variable, changing rapidly in an unpredictable manner.

\footnotetext{
${ }^{3}$ In pre-existing (stable) environments behavioral change does occur, simply because some individuals invent novel solutions to an existing problem. Hence the likelihood of being an innovator has partly to do with creativity. Further, it is easier to experiment and develop new routines in a stable environment than in an unstable environment (see Feldman, 2000).
} 
Damanpour and Gopalakrishnan (1998) challenge this view and offer a more detailed framework by stating that environmental change has two dimensions that can influence innovation. The first is stability, which reflects the amount or frequency of change. The second is predictability which reflects the expectedness of change.

Following insights from ecology (see Levins, 1968), Hannan and Freeman (1989) also discern two dimensions of environmental change. The magnitude of change (which they call "variability") and the pattern of change (called "grain"), which is a combination of the frequency of change and the predictability of change. Thereby, the grain can be seen as reflecting the popular two-state conceptualization of environmental change.

\subsection{Recent experience and innovative behavior}

In studying the relationship between environmental change and innovation, a moderating role is played by performance feedback signals based on past experiences. The role of performance feedback in explaining innovative behavior is relevant for two reasons: (1) it signals the extent to which agents are able to cope with their environment and (2) it signals the future expectations of current behavior. Thereby, performance feedback can be an important criterion when deciding to adjust the current behavioral repertoire. The more recent the feedback on past behavior, the greater the signaling value for future behavior. On the other hand, using feedback that is too old to guide future actions can lead to maladaptive behavior (Barnett and Hansen, 1996). As a result, following Cyert and March (1963) and Greve (1998), we limit ourselves to the most recent feedback signals the agents have received. Further, unpredictable environmental change fosters increased outcome uncertainty (Sutcliffe and Zaheer, 1998). Therefore, the feedback signals on past behavior lose predictive value regardless of how well someone is currently doing. This means that the value of signals from past experience is always contingent on environmental variability.

There is a long established research tradition on performance feedback learning for individuals (see Bandura, 1977; Betsch et al., 1998; Bower and Hilgard, 1981; Homans, 1974). On the organizational level, Lant and Montgomery (1987) and Greve (1998) developed general behavioral models to explain behavioral change, including innovation, which come very close to Slevin's model. Like Slevin, Greve derived his ideas from early behavioral theorists (e.g. Cyert and March, 1963; Levitt and March, 1988) considering adaptation - developing novel behavior - as the product of experience by making the probability of change conditional on the subject's history. Greve hypothesized that as current performance nears historical and social aspiration levels, there is a gradual decline in the likelihood of behavioral change. If current performance is above the aspiration levels, then the likelihood of behavioral change also diminishes. Following March (1988), Greve used an empirical criterion, aspiration level, on the basis of which individuals decide whether or not their performances were satisfactory. Greve confirmed his ideas when he tested them in several empirical studies on strategic changes, R\&D intensity, discriminating innovator firms from non-innovator firms and innovation rate.

\subsection{Economic status and innovative behavior}

Another explanatory model for innovative behavior was developed by a small group of researchers, with Cancian (1967, 1976, 1979 ) as the frontrunner. This group employed economic status as an explanatory variable. Cancian premised his model on the idea

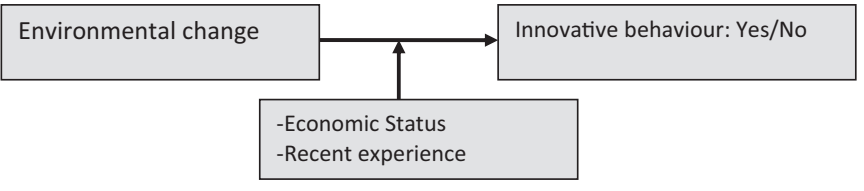

Fig. 1. General research model on innovative behaviour.

that each individual strives for being high-status ${ }^{4}$ rather than lowstatus, and consequently he modeled the effect of economic status on innovation.

Cancian (1967) defined economic status as the ranking of an individual relative to others in a hierarchy of resources. He predicted a curvilinear effect of economic status on innovation through a complex, and later heavily criticized, line of reasoning (see Gartrell, 1977; Morrison et al., 1976).

However, some of the proposed basic arguments were theoretically sound. He noted that high-status agents are inhibited when it comes to risking innovation, since they have the most resources to lose and do want to put their position at stake. Conversely, lowstatus agents are more likely to be innovative. On the other hand, the wealth of high-status agents facilitates innovative behavior since they can afford the risk, while the low-status agents cannot.

For agents that can be classified as middle-status, there are enough resources to innovate, but resources are not abundant enough to put their position at stake. However, they are doing well enough to have no need for innovation. The Cancian model has never been confirmed except for some anecdotal evidence (Cancian, 1979), but his theoretical propositions have cast a serious doubt on the previously assumed positive relationship between economic status and innovation (Rogers, 1995). Still, recent studies show that economic status plays an important role in explaining innovative behavior for individuals (Van Rijnsoever and Donders, 2009; Van Rijnsoever and Oppewal, 2012), organizations (Massini et al., 2005), and even animals (Reader and Laland, 2001).

We would like to make explicitly clear that economic status and recent experience are linked to each other on a conceptual level. Status can be seen as (partly) the accumulated resources resulting from a series of past experiences. If performance is good, an agent may rise in status, if performance is poor, the agent's status can go down too.

\section{Research model}

In this section we build our theoretical argument and formulate accompanying hypotheses to explain innovative behavior. Fig. 1 displays our research model.

\subsection{Comparing individuals and organizations}

In building our theoretical model, we hypothesize about what effects our variables would have on the position of the innovation boundary. Our theory is built from a universalistic perspective (Kruglanski, 1975; Stevens, 2011), meaning that it should hold regardless of the population of agents (individuals or organizations) to which it is applied. We therefore assume that agents choose the behavioral alternative with the highest utility. Assuming that both individuals and organizations are utility maximizing agents, we formulate hypotheses that are applicable to both types of agents.

\footnotetext{
${ }^{4}$ Cancian considered individuals as homogeneous with respect to their aspirations (everyone wants to be high-status, or at least, people would rather be rich than poor, but he left this issue implicit, and was severely criticized for this assumption (Rogers, 1995).
} 
Nevertheless, as cautioned by Greve (1998), there are limitations to comparing individuals with organizations. Organizations are more complex entities than individuals, since they consist of multiple agents. This complexity inhibits organizations more than individuals from adapting their behavioral repertoire (see Hannan and Freeman, 1984). First, organizations often have many sunk investments (e.g. plant, equipment) that are not easily transferred to a new behavioral regime. Second, the decision makers within an organization usually do not have the full overview of the relevant or required information on which to base decisions to change. Third, organizations can be seen as coalitions of stakeholders with different interests (Cyert and March, 1963; March, 1994). If the interest of one of these groups is threatened, the resulting political processes can greatly hinder the organization's capability to change its behavior (Hannan and Freeman, 1984). The latter also implies that organizations with a simple but strong hierarchical structure have a greater flexibility because the organizational decision makers have more power to enforce decisions (Hannan and Freeman, 1984).

It should be noted that individuals can also get locked into behavioral patterns, which leads to behavioral inertia. Betsch et al. (2004), for example, demonstrated that the degree to which a skill is routinized is negatively related to the ability to change behavior. Such inertia on the individual level further hampers organizational abilities to change routines.

Internal inertial forces become stronger as the size and complexity of the organization increases. This means that the behavior by organizations will differ increasingly from what is expected from a utility perspective as organizational complexity increases. For the current research, this means that the hypotheses mainly apply to individuals and relatively small and simple organizations in which individual managers are able to instigate organizational change. Examples are small and medium-sized enterprises (SMEs) and start-up firms led by a single entrepreneur. For larger companies the theoretical effects will be less pronounced, but may also be found.

\subsection{Innovative behavior}

Following Slevin (1971), we regard innovative behavior as a dichotomous variable: either the agent displays innovative behavior, or the agent does not display innovative behavior and remains inert. Slevin reasons that agents display innovative behavior when they cross the so-called innovation boundary; that is, when rewards expected from innovation exceed total costs.

The basic model of Slevin assumes that agents have perfect information to make such a decision. However, most decisions with regard to innovation are made with imperfect information about future performance. This imperfect information adds uncertainty to the position of the innovation boundary; agents are thus unable to determine its exact position. The main source of this uncertainty is changing environmental conditions.

\subsection{Environmental change}

The display of any form of innovative behavior may incur different types of risks depending on changes in the environment (Lant, 1992; Suarez and Lanzolla, 2007). An explicit assumption is that environmental change is exogenous from the agent, in our studies we measure the influence of environmental change on behavior, but not how this behavior influences the environment. We recognize this fact, but we do not model it here. Further, though we also recognize the complexity of environmental dynamics, we limit ourselves in the current study to the effects of variability (the frequency of change) on the likelihood of displaying innovative behavior, for the sake of parsimony. The magnitude of the change is kept constant, so we can only infer that the magnitude is larger in one environment compared with the other but we cannot quantify this. Further, predictability of environmental variability can be assessed by agents on the basis of past environmental variations but is not modeled as a separate dimension.

Based on the aforementioned criteria, we discern two types of environmental conditions: stable and variable. A stable environment knows one moment of novelty for the agent, which is the starting point in time $\left(t_{0}\right)$. This starting point is the time when an agent enters the environment. A stable environment remains unchanged from the beginning. A one-time successful novel response is all that is required from an agent to adapt to the situation. This novel response can originate from ad hoc problem solving. It can be further refined and developed into a routine or personal skill.

Though there is little need for an agent to display innovative behavior, a stable environment does provide opportunities to experiment with new solutions and further improve existing routines (Feldman, 2000). However, in an environment that is (theoretically) absolutely stable, an optimal routine will be reached at a certain moment after which no further improvement is possible. In reality, even a stable environment has ongoing environmental change, so there will always be some change in routines (Feldman, 2000).

When viewed from a risk taking perspective, it can be said that in such a theoretically stable environment with well-established behavioral patterns and routines, innovation is riskier than continuing those patterns. As soon as the environment starts to change, the chances of success of any innovative behavior increase dramatically. A one-time punctuated change provides opportunities for innovation. Agents that respond quickly can gain a first mover advantage (see Lieberman and Montgomery, 1988) but they also run the risk of their response not matching the new environmental conditions.

The theoretical opposite to a stable environment is a fast and randomly changing environment. In a completely randomly changing environment, there is no discernible pattern from which a prediction on future environmental changes can be made. This type of environment requires constant innovative responses, and does not allow for the development of operational routines (Broder and Schiffer, 2006). In environments where the rate of change forces agents to systematically adapt their operational routines on a regular basis, ad hoc problem solving no longer suffices and dynamic capabilities are required (Zollo and Winter, 2002). These dynamic capabilities are only effective if the rate of adaptation is faster than the rate of environmental change.

In a fast and randomly changing environment, the risk of change becomes equal to the risk of remaining inert because there is no time for the new behavior to develop into an effective skill. As such, the chances of successful innovative behavior are never greater than the chances of success by remaining inert because a match between behavior and environment is purely random. In reality, the rate of environmental change will be somewhere in between the theoretical conditions of perfect stability and perfect variability.

The rate of environmental variability decides the location of the innovation boundary and the certainty of this location. In a stable environment, the agent knows, based on past information, where this boundary is, whereas in a changing environment, one does not know what the rewards of current behavior will be. The larger the degree of environmental change, the more uncertain is the position of the innovation boundary.

\subsection{Moderator 1 - recent experience}

Based on their recent experience, agents learn to repeat and incrementally improve successful behavior (Bandura, 1977; Raelin, 1997), while unsuccessful behavior is more likely eventually to be 
extinguished (Gavetti and Levinthal, 2000; Hutchins, 1991; Van de Ven and Polley, 1992). If a recent behavior was unsuccessful, a switch to another behavioral mode is expected (Homans, 1974; Lave and March, 1993; Sitkin and Pablo, 1992). When a recently taken action is rewarded, it is more likely that the agent will perform that action again. This effect has been found for organizations (Kaplan and Henderson, 2005; Van de Ven and Polley, 1992). For individuals, this outcome is called the "success hypothesis" (Homans, 1974).

Hypothesis 1. In a stable environment, the more positive recent experience is, the more likely the repetition of innovative behavior will be.

In an increasingly variable environment, the rewards for routine behavior become more random and it is uncertain whether there is a match between the routine and environmental demands. We offer two alternate explanations as to why there is still a relationship between recent experience and innovative behavior. First, in variable conditions, recent experience gives less guidance as to future behavior, which should make the relationship formulated in Hypothesis 1 disappear (Houston and McNamara, 1981). However, since there is no apparent alternative, recent experience may be the most logical guide to future behavior. Agents that receive positive feedback from recent behavior incur a sense of certainty that the strategy worked, while this certainty does not exist for other behavioral alternatives. Further, the agent has already gained some experience with the behavior, which is the first step to routinization. Switching to an unknown alternate behavior involves additional switching costs (Klemperer, 1987), which decrease the chances of behavioral change.

Second, instead of developing innovative behavior into an operational routine, agents develop a dynamic capability that enables them to adapt their operational routines to better cope with environmental change (Zollo and Winter, 2002). In this case, the recent experience signals how well routine adaptation functions. Again, recent experience has signaling value for future outcomes unless the frequency of environmental change becomes larger than the ability of the agent to adapt its operational routines.

In the case of the first explanation (no apparent alternative), recent experience has less signaling value than in a stable condition, implying that the relationship between recent experience and the repetition of innovative behavior is weaker in a variable condition than in a stable condition. In the case of the second explanation (dynamic capabilities), this need not be the case. Recent experience has signaling value for the ability to change operational routines. There is no apparent reason to expect a difference with the effect of recent experience in the stable condition. We formulate the strength of the relationship as a separate part of the following hypothesis:

Hypothesis 2a. In a variable environment, the more positive recent experience is, the more likely the repetition of innovative behavior will be.

Hypothesis 2b. This relationship is less strong in a variable than in a stable environment.

\subsection{Moderator 2 - economic status}

Economic status is the position of an individual relative to other people in the hierarchy of resources owned in a population (Cancian, 1967). Often such resources need to be invested for the agent to display innovative behavior. Resources are thus an enabler of innovation for both organizations (Barney, 1991), and individuals (Rogers, 2003).

Economic status was predicted to have different influences on the display of innovative behavior. If we look at the problem in terms of risk, we can argue that the low-status agents cannot afford not to innovate (or they will become extinct) and the high-status can afford to innovate and are perhaps obliged to do so as a means of preserving their positions. Those of middle-status have no incentive to innovate (Cancian, 1967).

A related argument comes from Homans (1974), who states that low-status individuals strive to become middle-status. Conforming to existing norms, rules and practices does not result in a rise in status. Since they have little to lose, there is little need for them to conform to existing norms, rules and practices. The only way to rise in status is to be deviant and display innovative behavior. The middle-status would like to become high-status. However, since they do not wish to put their position at stake by investing in innovation, they need to conform to existing norms, rules and practices; therefore they imitate the behavior of the high-status. High-status individuals have the freedom to decide what the existing rules, norms and practices should be and the means to experiment with alternate approaches. They might even be required to so in order to remain ahead of the middle-status.

For organizations a similar argument has been developed by Massini et al. (2005), who rank organizations according to the routines they have adopted. They argue that firms imitate a reference group but that these reference groups differ for firms that are ranked above the average and those that are ranked as average or below. The former see other high-ranked firms as peers, while the rest view the average organization as their reference group. Firms below the population average want to move to the population average and thus need to become innovative. Firms that are average have already fulfilled this aspiration, so there is no need for them to innovate. Firms that are ranked above the average want to distinguish themselves even more from the average and keep up with the other high-ranked firms that they view as their reference group.

These arguments stress the lack of incentive to innovate for the middle-status. We hypothesize a U-shape between economic status and innovative behavior in a stable environment; the middle-status is less innovative while the high-status and the lowstatus are more innovative.

Hypothesis 3. In a stable environment, high-status and low-status agents are more likely to display innovative behavior than middlestatus agents.

In a variable environment, all groups have equal knowledge about the future, and therefore the risks of innovation are equally divided. High-status individuals, however, have the advantage of more resources to spend than do low- and middle-status individuals. They may either keep the resources in buffer to enable them to remain inert until uncertain times have passed, or use their resources to reduce the risk of innovative behavior. On an individual level it is unclear which alternative will prevail. The outcome likely depends on personal characteristics.

On the organizational level, Cyert and March (1963) also argue that resources can act as a buffer against environmental change but can also facilitate adaptive behavior. Cheng and Kesner (1997) found that this difference can be explained by the orientation of organization. Internal-oriented firms are more likely to remain inert, while external-oriented firms are more likely to innovate. For now we formulate two rival hypotheses.

Hypothesis 4a. In a variable environment, there is a positive relationship between economic status and innovation.

Hypothesis $\mathbf{4 b}$. In a variable environment, there is a negative relationship between economic status and innovation. 


\subsection{Covariate - global innovativeness}

The discussion above implies that differences between agents might explain and partly influence the display of innovative behavior. Since our model is tested empirically on the individual level, we limit ourselves to personal characteristics.

The most relevant is global innovativeness (Kirton, 1976). ${ }^{5}$ This general personality trait relates to how innovative people are in the process of problem-solving. According to Kirton (1994), people try either to improve on existing solutions (adaption) or to find new solutions (innovation). Adaptive individuals are claimed to be more precise, more reliable, to think within the existing frameworks, and to prefer working with well-established procedures. Innovators, on the other hand are less focused on details and less reliable. They propose more radical perspectives and are more inclined to challenge established rules and authority (Kirton, 1976, 1994). Finally, innovators accept more risk than adaptors (Kirton, 1994). This trait directly relates to the most important characteristics of innovative behavior; risk and novelty.

Research has shown that global innovativeness is related to the early adoption of consumer products (Im et al., 2003; Van Rijnsoever and Donders, 2009; Vishwanath, 2005), the function of managers in organizations (Foxall et al., 1992), research collaboration of scientists (Van Rijnsoever and Hessels, 2011; Van Rijnsoever et al., 2008), and the innovative intentions of entrepreneurs (Marcati et al., 2008). Therefore it is included as a covariate.

In the stable condition, individuals can estimate the position of the innovation boundary based on their recent experience. This allows them to calculate which choice is most advantageous with relative precision. We therefore expect little influence of global innovativeness on the display of innovative behavior. But we do expect that in the variable condition, where the position of the innovation boundary is unknown, personal attributes influence the decision to display innovative behavior. Therefore, it is likely that global innovativeness is positively related to innovative behavior in a variable condition.

Hypothesis 5. There is a positive relationship between global innovativeness in the variable condition, but not in the stable condition.

\section{Empirical studies}

We tested the hypotheses from our theoretical framework in two studies. The first study is a controlled laboratory experiment. The second study is a discrete choice experiment (DCE) to measure stated preferences for innovation.

\subsection{A note on sampling}

In both studies, the participants are students. According to Stevens (2011), there are two factors that determine whether the use of student samples is appropriate.

The first is the scope of the theory. A theory can be formulated in a universalistic manner or in a particularistic manner (Kruglanski, 1975). Stevens (2011) argues that a universalistic theory applies to all populations and therefore a student sample is not inherently better or worse than any other sample. Particularistic theories, on the other hand, are context-specific demand samples that represent the population characteristics of the specific context. Since we

\footnotetext{
${ }^{5}$ The term global refers to the fact that this is a general personality trait, and that it is different from other types of innovativeness found in the literature, such a domain-specific innovativeness, product-specific innovativeness or actualized innovativeness (Van Rijnsoever and Donders, 2009).
}

formulated our theory from the perspective of utility maximizing agents, and our hypotheses are consistent with both individual and organizational level arguments, our theory can be viewed as universalistic. This is the point of departure for study 1 . However, since we are interested in applying the theory to innovation decisions in a business setting, we apply it to such a specific context in study 2 using a discrete choice experiment (DCE). A DCE allows us to transfer the universalistic research context from study 1 to a more realistic setting.

The second factor is the primary purpose of the study. According to Stevens (2011), the purpose can be to demonstrate internal validity or to optimize external validity (often one is scarified to the other). Laboratory experiments such as study 1 often have a high internal validity and a low external validity, due to the stylized setting and homogeneity of the sample (Campbell and Stanley, 1966). The primary purpose of this paper is to develop a model that is internally valid, since this quality is often lacking in innovation research. Internal validity is best optimized using a homogenous sample. Given the universalistic nature of our theory the choice of sample could be argued as irrelevant (Stevens, 2011). However, given the differences between individuals and organizations, we do proceed with caution (see the discussion above) by arguing that the effects found mostly apply to less complex organizations. Furthermore, many of the students selected for these studies are familiar with the concept of innovation. This is especially true for study 2 , which is context specific. This increases the transferability of our results to a real life situation.

\subsection{Study 1}

The purpose of this study was to test whether our theoretical model receives empirical support in a behavioral laboratory experiment.

\subsubsection{Sample and data collection}

The subjects for the experiment were students from different departments of Utrecht University and the Utrecht University of Professional Education. The total number of participants was 57, ranging in age from 18 to 27 years (mean age: 21.42 years). The group consisted of 35 males and 22 females. Many participants followed either a bachelor or a master program related to innovation management (43.9\%) and were thus familiar with the topic of innovation. However, there were no noticeable differences in outcomes between these students and those that followed other programs. The subjects were divided into eight experimental groups of 5-9 members. To enhance motivation, all were promised a reward relative to their performance in the experiments, the average being $€ 8$ for a participation time of $75 \mathrm{~min}$. Subjects were told that they are taking part in a game and had the opportunity to earn money at the end if they collected a certain number of points. The goal of the game was stated clearly: the participants should attempt to collect as many points as possible. Each group was placed in an experimental setting consisting of two rooms (room A and room B). The two rooms were connected, but it was not possible to see into room A when sitting in room $B$ (see Fig. 2).

In room $A$, there was a blackboard displaying the names of the players and the points they collected after each round. There were chairs for the players to sit on; a short questionnaire and an envelope were kept on each chair. The questionnaire contained a number of questions designed to measure personal characteristics. Players were requested to fill-in the questionnaire first.

Inside the envelope there was a badge carrying a number, which the observers used to identify each player. Players were informed of the number of points allocated to each at the start via a note in the envelope. The number of starting points was not the same for all players: the points were randomly distributed between 400 and 


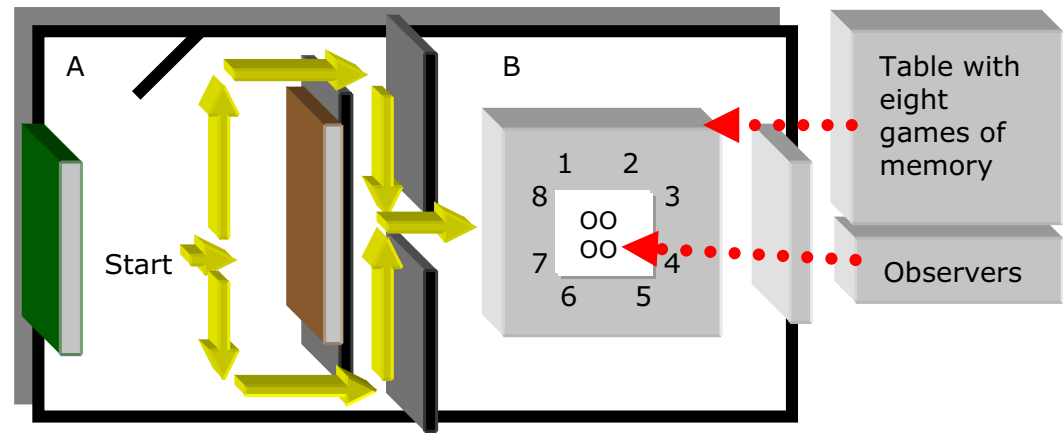

Fig. 2. A model of the experimental setting.

680 , with steps of 40 points. These points served as the indicator of their resources (i.e. their economic status). If a player had a negative number of points at the end of a round, he or she was obliged to quit the game. The number of starting points for each player was written on the blackboard for all players to see.

Additionally, a board was kept in the room with the goals, rules and instructions of the game written on it.

In room B, there was a large square table with eight chairs. In the middle of the table four observers were present. At each seat, a game of Memory ${ }^{\circledR}$ with 20 cards was set up. The games were separated by screens. There was also a large board near the entrance with the rules of the game. A researcher was present to announce the rounds and to calculate the points.

\subsubsection{Procedure}

The game had nine rounds. At each round the subjects could choose to:

- Pay 40 points and remain in room A;

- Pay 70 points and pass through to room B, where the player found a memory game to solve, consisting of 10 pairs. If the player succeeded in solving it, he or she could receive up to 240 points. Players did not know in advance what was in room $B$.

The memory game is played by flipping two cards at the same time. If a player finds a pair, the cards are left open; if a player does not find a pair, the cards are flipped back. The game concludes when all ten pairs are found. To simulate environmental change, four of the experimental groups received a new combination of cards to solve in each round (this was the variable condition) but within each round all players received the same task. The other groups received the same game over the first eight rounds and only received a novel task in the ninth.

For each second the fastest player was faster in solving the game than the second best, he or she received 5 points, up to a maximum of 240 points. The following players who solved the game also earned 5 points per second, until the cumulative total of points earned over all the players was 240 . This means that if all subjects decided to go to room $B$, the average loss would have been 40 points, which is equal to staying in room A. Hence, the rational chance of displaying innovative behavior is equal to $50 \%$. The difference between innovation and non-innovation is that the uncertainty attached to innovation is larger.

The equal expected benefits between innovation and noninnovation are assumed to have no influence on our hypotheses test, since the hypotheses are formulated independently of the chances of success of innovation. The expected benefits of innovation do influence the overall likelihood of displaying innovative behavior, but this is not stated in our hypotheses. The expected benefits of innovation were kept constant throughout the experiment in both conditions.
Observers reported the time that the subjects took to solve the task. All observers received training to observe in the same manner. If a player did not follow the rules of the game, he or she was cautioned by the observer. A penalty was issued if a player broke the rules and gained a significant advantage by doing so. This happened twice during the course of our experiments. Both were minor corrections, and did not influence our results. Each round lasted two minutes, after which all players returned to room A, where the changes in scores were written on the blackboard. In the meantime, the observers laid out a new game of memory in room $B$ for the next round. In the stable condition, the puzzle in the final round differed from the previous puzzles to check whether skill development actually took place. After all nine rounds, the game was concluded and all players were paid their rewards.

\subsubsection{Measurement}

The variables measured and their indicators are provided in Table 1. Innovative behavior was operationalized by whether the individual took the risk of going into room B, where 70 points of resources were risked and where the greatest gains were to be made. In the literature, many measures of innovation have been used. For individuals this is often measured as the relative time of adoption of a new product (see Rogers, 2003; Van Rijnsoever and Donders, 2009; Van Rijnsoever and Oppewal, 2012). For organizations various measures are used (see Rosenkopf and McGrath, 2011), among which are; patenting activities (Benner and Tushman, 2002; Sørensen and Stuart, 2000), having developed new product or process innovations (Laursen and Salter, 2006), changing strategies (Greve, 1998), or adopting new routines (Massini et al., 2005). We acknowledge that innovation is a broader, more multidimensional and context specific concept than measured here. However, this stylized representation of innovative behavior does contain the two most important elements of innovation; risk-taking and novelty (Benner and Tushman, 2002).

According to Rosenkopf and McGrath (2011), novelty can be characterized by the mechanism through which it is achieved, for example, purchasing a new product or investing in R\&D. Further, novelty takes place in a specific context, which provides a reference point for assessing novelty such as the improvement of a product compared with a previous product generation.

In the current experiment, the mechanism is going to room $B$ and the context is the departure from the familiarity of room A to the unknown and novel situation of room $B$. This novelty decreased as trials progressed, which corresponds to the difference between the novel response and routinization. Finally, the risk-taking element is simulated by the unknown returns of the investment. Even though this measure of innovation is stylized and the context is simplified, it does cover the aforementioned fundamental elements of innovation. Since novelty decreases as the trials progress, we acknowledge that the emphasis of the measure is more on risk-taking than on 
Table 1

The indicators for the variables in the model.

\begin{tabular}{|c|c|}
\hline Definition & Indicator \\
\hline \multicolumn{2}{|l|}{ Dependent variable } \\
\hline Decision to innovate or not & To enter room B: No $=0$, Yes $=1$ (nominal scale) \\
\hline \multicolumn{2}{|l|}{ Independent variables } \\
\hline Environmental change & Whether the task varies at each round or not (variable $=1$, stable $=2$ ) (nominal scale) \\
\hline Recent experience & The change in points in the previous round (from -70 to +170 points) (ratio scale) \\
\hline Economic status during the experiment & $\begin{array}{l}\text { Points a subject had at the beginning of a round. During the experiment, the extremes were } \\
-30 \text { and } 845 \text { points (ratio scale). }\end{array}$ \\
\hline Innovation during the previous round & Whether room B was entered in the previous round: $\mathrm{No}=0$, Yes $=1$ (nominal scale) \\
\hline Round & The round number (ordered nominal scale) \\
\hline
\end{tabular}

novelty; especially in later trials. We do believe that it is a valid proxy for innovative behavior in the current setting.

Using the questionnaire, global innovativeness was measured using a translated adapted version of the 32-item scale by Kirton (1976). The Chronbachs Alpha was 0.81 , which is a very satisfactory level of internal reliability.

\subsubsection{Analysis}

To assess the extent to which individuals indeed learned to routinize their behavior, we plotted the average amount of seconds subjects took to complete the task each round in both experimental conditions. The differences in the time it took to complete the puzzle in each trial were calculated using repeated measures ANOVA. Furthermore, we used a paired sample $t$-test to calculate whether the time to solve the game declined between rounds 2-4 and rounds $6-8$. At the individual level, we calculated the finish time and ranked each individual relative to their experimental group. We then related the cumulative rankings of rounds $2-4$ and rounds 6-8 using a Spearman correlation. This enabled us to determine whether the subjects solved the puzzle at consistent speeds and if others were lagging behind. The results of the final rounds were compared using ANOVA over the different experimental conditions and experimental groups.

To test our hypotheses, a mixed-logit model was fitted using the $\mathrm{R}$ program ( $\mathrm{R}$ Development Core Team, 2010) and the lme4 package (Bates and Sarkar, 2006). The models contain a random intercept, dependent on the individual subjects, to account for unobserved individual differences. We added the interaction terms of recent experience and economic status to environmental change to establish whether there were significant differences between the experimental conditions; if there were any differences, an analysis was performed separately for each condition. Recent experience was added to the model as independent variable measured by the difference in points in the previous round (at $t-1$ ); the addition of this variable led to round 1 being excluded from the model, because there were no results prior to round 1. An advantage of excluding round 1 is that effects that result from growing accustomed to the game are largely excluded from the analysis. Next to a linear term, the squared value of economic status (divided by 1000 for ease of interpretation) was added to test the U-shaped relationship. As an additional control variable, we added whether or not a subject had displayed innovative behavior at $t-1$. This allowed us to discriminate between the results of innovators and non-innovators. Additionally, global innovativeness was added to the model as a linear predictor. Prior analyses revealed that other potential covariates such as gender, age, or education program, did not influence the results and were unrelated to innovative behavior. To save degrees of freedom, these covariates were not included in the model. One case was dropped from the model because it was classified as an outlier with regard to global innovativeness. This case was 3.04 standard deviations (SD) below the mean; the next lowest case was only 1.56 SD below the mean. Finally, the last round was excluded from the analysis because a different task was administered and to control for 'endgame' behavior.

\subsubsection{Results and discussion}

Table 2 shows the percentages of innovators and solvers over all of the rounds in both of the conditions. The first thing to note is that the actual number of innovators was above the calculated innovation threshold in both conditions. It appears as though the respondents were biased toward innovation. In the first eight trials, the subjects in the stable condition went to room B more often than the subjects in the variable condition. Subjects preferred to innovate in a stable condition rather than in an uncertain variable condition. It seems as though people prefer to learn a solution once and optimize it further rather than having to make continuous changes in order to be successful, which is in line with Feldman (2000).

Though more people went to room B in the stable condition, it is surprising to note that there is no difference in the percentage of solvers between both conditions for individuals who went to room $B$. This finding suggests that environmental variability did not hamper performance. The subjects were quite good at estimating their chances of success in both conditions. It also indicates that all puzzles were solvable by a good number of people.

As shown in Fig. 3, there were significant differences between the two conditions in terms of time taken to solve the task over the first eight rounds, $F(1,55)=18.462, p<0.01$; the final round was excluded because the task varied in the stable condition.

The difference in average time to solve the task between rounds 2-4 and rounds 6-8 was significant both in the stable condition,

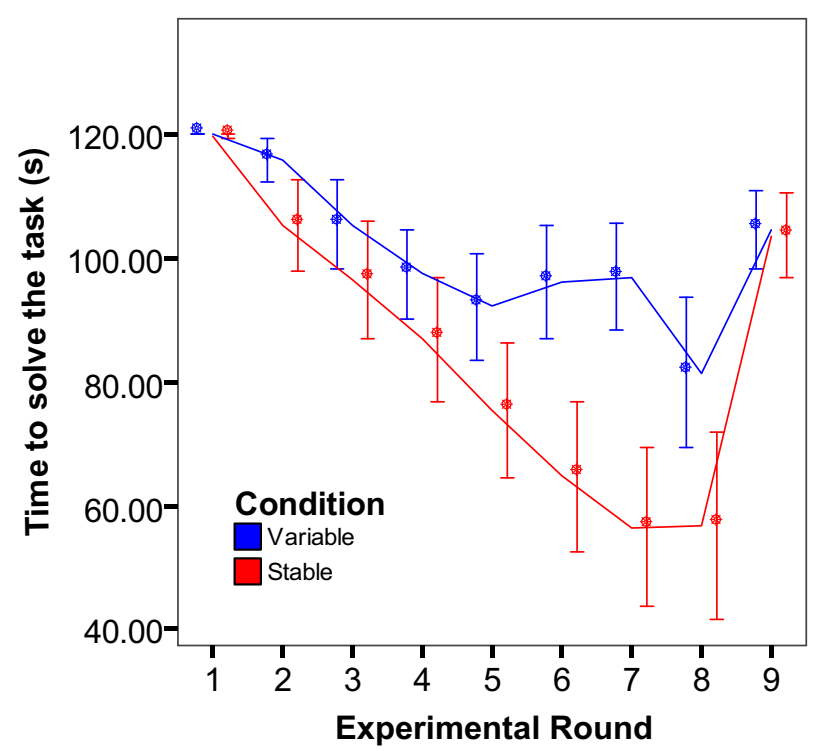

Fig. 3. The average time to solve a task over different experimental rounds for both conditions. 


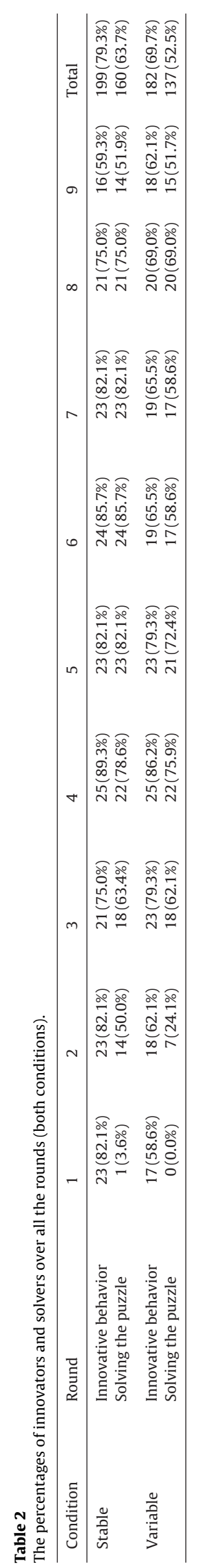

$t(27)=6.654, p<0.01$, and in the variable condition, $t(28)=4.384$, $p<0.01$, but this effect is less strong. This is an indication that skills developed better in the stable condition than in the variable condition.

There was also a significant correlation at the $5 \%$ level in rankings between rounds $2-4$ and rounds $6-8$ in both conditions (condition variable: $\rho=0.448, p=0.015$; condition stable: $\rho=0.423$, $p=0.025$ ). This finding confirms that the same individuals were first to solve the puzzle, giving more evidence of the development of skills over time. There was no difference in the time taken to solve the puzzle during the final round between both conditions, $F(1,55)=0.50, p=0.823$.

As expected the performance of subjects in the last round of the stable condition declined dramatically. However, the decline in performance in the variable condition during the last round was unexpected because there was not a significant deviation from the pattern of puzzles established in the previous rounds. A possible explanation to this might be that subjects were 'endgaming' becoming more cautious of their performance during the last round and not daring to risk their precious resources.

Overall, the subjects acquired distinct skills in the two different conditions. In the stable condition, the subjects mastered a puzzle that was repeated in each round, whereas in the variable condition, the subjects learned techniques for solving a random puzzle rather than memorizing one specific puzzle. The former resembles a specific operational skill, while the latter resembles a dynamic capability (Zollo and Winter, 2002).

Table 3 displays the results of the mixed-logit models that predict innovative behavior.

Model 1 shows that there is no difference in the likelihood of displaying innovative behavior between the two environmental conditions. The moderating effect of economic status on the relationship between environmental variability and the likelihood of displaying innovative behavior is confirmed.

Hypothesis 1 made a prediction about the effect of recent experience on innovation in the stable condition. This effect is indeed significant in model 2. Hypothesis 2 a made the same prediction for recent experience in a variable condition and is also supported in model 3. Model 1 reveals that a difference with regard to the effects of economic status is visible between the two conditions, but not for recent experience. This causes us to reject Hypothesis $2 b$. With regard to the effect of recent experience, there is no difference between the two conditions. This supports the notion that people in the variable condition developed dynamic capabilities. Further, this finding shows that recent experience is a guide for future behavior in both a variable and a stable condition.

Hypothesis 3 predicted that high-status and low-status individuals are more likely to display innovative behavior than middle-status individuals in a stable environment. Model 2 shows that this U-shaped effect is supported with the turning point of the curve at 314 points, a realistic value. This follows the propositions of Cancian (1979), Homans (1974) and Massini et al. (2005).

The rival Hypotheses $4 \mathrm{a}$ and $4 \mathrm{~b}$ predicted a relationship between economic status and innovation in the variable condition, but neither is strongly confirmed in model 3 . There is a slight positive relationship, significant at the $10 \%$ level, which indicates some support for Hypothesis 4a.

Finally, there is a positive relationship between global innovativeness and innovative behavior in the variable condition, but not in the stable condition. This supports Hypothesis 5.

\subsection{Study 2}

For our second study, a discrete choice experiment (DCE) was conducted (Batsell and Louviere, 1991; Hensher et al., 2005; Louviere and Woodworth, 1983). DCEs are a common technique 
Table 3

The results of the random-effect logistic regression models.

\begin{tabular}{|c|c|c|c|}
\hline Variable & Model 1 - innovation total & Model 2 - stable & Model 3 - variable \\
\hline Intercept & -4.277 & 2.087 & $-3.66^{*}$ \\
\hline Variance random intercept & 0.495 & 1.087 & 0.249 \\
\hline Recent experience & $0.025^{* * *}$ & $0.030^{* *}$ & $0.024^{* * *}$ \\
\hline Previous innovation & 0.378 & $1.074^{*}$ & 0.551 \\
\hline Economic status & 0.006 & $-0.020^{* *}$ & $0.003^{*}$ \\
\hline Economic status $^{2}$ & -0.004 & $0.032^{* *}$ & \\
\hline Global innovativeness & $0.047^{* *}$ & 0.029 & $0.043^{* *}$ \\
\hline Environmental change $($ variable $=1$, stable $=2)$ & 5.85 & & \\
\hline Round & -0.386 & -0.665 & -0.287 \\
\hline Round 2 & $-0.853^{* *}$ & $-1.208^{*}$ & -0.678 \\
\hline Round 3 & 0.406 & -0.565 & $1.987^{* *}$ \\
\hline Round 4 & 0.221 & 0.411 & 0.061 \\
\hline Round 5 & -0.503 & -0.632 & -0.396 \\
\hline Round 6 & 0.288 & 0.838 & -0.085 \\
\hline Recent experience $\times$ environmental change & -0.001 & & \\
\hline Innovation in previous round $\times$ environmental change & 0.082 & & \\
\hline Economic status $\times$ environmental change & $-0.024^{* *}$ & & \\
\hline Economic status ${ }^{2} \times$ environmental change & $0.033^{* *}$ & & \\
\hline Number of observations & 392 & 196 & 196 \\
\hline$N$ & 56 & 28 & 28 \\
\hline Log likelihood & -171.6 & -71.06 & -97.00 \\
\hline
\end{tabular}

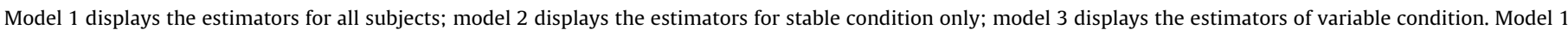

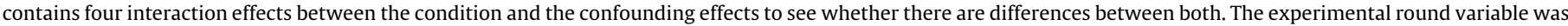
fitted as an ordered fixed factor.

${ }^{*} p<0.1$.

${ }^{* *} p<0.05$.

*** $p<0.01$.

to measure stated preferences and are widely used in the fields of transportation, marketing and various branches of economics (e.g. health, agricultural and environmental economics), but not in innovation studies. DCEs rely on random utility theory (Batsell and Louviere, 1991; Louviere et al., 2010; Manski, 1977), and have been shown to be accurate forecasters of revealed choice. They assume that each agent attaches a certain amount of utility $U_{i}$ to each behavioral alternative $i$ (in this case innovation or noninnovation). This utility consists of an observed part $V_{i}$, and an unobserved part $\varepsilon_{i}$. The value of $V_{i}$ can be inferred from the set of $j$ attributes that are associated with alternative $i$. Each attribute is weighted by a parameter coefficient $\beta_{i j}$. In the current study, environmental change, recent experience and economic status are the attributes.

In a DCE respondents receive a questionnaire containing a series of choice tasks. Each task contains a number of alternatives from which the respondent can choose a preferred option. Based on the levels of attributes that are associated with each alternative, the respondent can state for each task which alternative he or she prefers. Usually, there are multiple versions of the questionnaire. Preferably, over the choice tasks and versions, the attribute levels vary systematically in such a manner that the overall DCE contains a full-factorial design.

A big advantage of using DCE is that the choice tasks can be framed to represent real decisions. This increases external validity and helps to compensate for the shortcomings of study 1 . A second advantage is that the level of the independent variables is given by the experimental design, which greatly reduces the risk of common method bias (Podsakoff et al., 2003). A downside is that DCEs usually measure stated preferences instead of actual behavior. Since actual behavior was already measured in study 1 , the aim of study 2 was to replicate the results from study 1 in a more realistic context, outside the stylized setting of the laboratory, thereby enhancing the validity of our results. As such, study 2 complements study 1 . However, it ought to be noted that we did not measure behavior in a real life context.

\subsubsection{Sample and data collection}

Respondents were students in bachelor and master courses related to innovation. The courses were: Introduction to Technology and Innovation (bachelor level 1), Innovation Systems (bachelor level 2), Managing Innovation Projects (bachelor level 3) and Technology Related Venturing (master level 1). Consequently, all were familiar with the concepts of innovation on different levels.

A total of 142 questionnaires were distributed during course lectures over a period of two weeks. ${ }^{6}$ To incentivize respondents to complete the questionnaire, it was announced that they could win a gift certificate of $€ 20$. The questionnaire was completed by 104 individual respondents, giving a response rate of $73 \%$. The respondents' ages ranged from 18 to 27 years (mean age 20.88 years). There were 19 females and 85 males who responded; this is representative for the population of students that follow these programs. The vast majority followed a bachelor or master program related to innovation management, but there was no difference in outcomes between these and respondents who studied in other programs.

\subsubsection{Procedure}

After a short introduction, each questionnaire started with an opening vignette in which the respondent was asked to image being an entrepreneur in a high-tech sector who could choose to invest in innovation or not. The generic term high-tech sector was used to prevent any respondents being influenced by the perceived familiarity of a specific technology or industry. Respondents were informed that they could choose to invest or not invest in innovation and that they could base their choice on the levels of three attributes: market conditions (representing environmental change), results from the previous investment (representing recent experience) and their firm capital (representing economic status) The exact vignette is given in Fig. 4.

\footnotetext{
${ }^{6}$ This was part of a broader round of data collection.
} 
Imagine that you are the owner of a small high-tech enterprise. The market in which you are active is highly stable; there is little change over the years, which makes the market very predictable*.

The annual costs for your enterprise are usually $\mathbf{€ 4 0 0 , 0 0 0}$.

This year you have opportunity to invest in a new innovative product. When you decide to invest, the costs for this year will be $\mathbf{6 8 0 0 , 0 0 0}$ (this includes annual costs). Because you do not know what your competitors will do, it is difficult to predict what the chances of success are for this investment.

There are two factors that can guide you in making a decision to invest or not.

- The results from a comparable investment in innovation you made a year ago. This is expressed as a positive or negative result. A negative result (loss) means that you did not earn back your investment. A result larger than $€ 0$ means that your returns are larger than the investment (profit). After a year it becomes clear what the results of the investment are.

Market research has shown that the results of investments in innovation for comparable enterprises vary from a loss of $\mathbf{€ 8 0 0 , 0 0 0}$ (no returns, only costs) to a profit of $€ \mathbf{1 , 7 0 0 , 0 0 0}$. On average the results of the investment are a loss of $\mathbf{€ 4 0 0 , 0 0 0}$ (this is equal to non-investment in innovation)

- Your firm capital. All your expenses are financed from this. If your firm capital is negative at the end of the year, your company goes bankrupt.

Market research has shown that firm capital of comparable enterprises varies between $\mathbf{€ 8 0 0 , 0 0 0}$ and $€ \mathbf{3 , 6 0 0 , 0 0 0}$. The average firm capital is $\mathbf{€ 1 , 6 0 0 , 0 0 0}$.

NOTE: You would like that your enterprise survives on the longer term. The coming years the annual costs and the costs for innovation will remain approximately the same. The values of the two factors are presented in the question.

To summarize: If you do invest in innovation, the expenses are $\mathbf{6 8 0 0 , 0 0 0}$. If you don't invest in innovation, the expenses are $\mathbf{6 4 0 0 , 0 0 0}$.

Fig. 4. Opening vignette. ${ }^{*}$ The description of the market varied by environmental condition.

\begin{tabular}{|c|c|c|}
\hline \multicolumn{3}{|c|}{$\begin{array}{l}\text { Suppose that you are in the earlier described scenario. Would you invest in } \\
\text { innovation or not? Take into account the factors and market conditions. Market } \\
\text { conditions are as follows: }\end{array}$} \\
\hline \multicolumn{3}{|c|}{$\begin{array}{l}\text { "The market in which you are active is very stable; there is little change over the } \\
\text { years, which makes the market very predictable." }\end{array}$} \\
\hline \multicolumn{3}{|c|}{$\begin{array}{l}\text { Below are values of the factors. Tick which decision you would make based on } \\
\text { this information. }\end{array}$} \\
\hline \multicolumn{3}{|c|}{ Factors } \\
\hline $\begin{array}{l}\text { Results from previous } \\
\text { investment }\end{array}$ & \multicolumn{2}{|c|}{$+€ 1,200,000}$. \\
\hline \multirow[t]{2}{*}{ Firm capital } & \multicolumn{2}{|c|}{$+€ 2,400,000 .-$} \\
\hline & 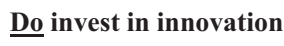 & Don't invest in innovation \\
\hline Expenses & $€ 800,000 .-$ & $€ 400,000 .-$ \\
\hline $\begin{array}{l}\text { Tick your preferred } \\
\text { option }\end{array}$ & $\mathrm{O}$ & $\mathrm{O}$ \\
\hline
\end{tabular}

You can read the factors as follows:

- The result from the previous innovation investment was a profit of $€ 1,200,000$. You thus have a positive experience with innovation. Compared to other entrepreneurs the profit of $€ 1,200,000$ is relatively high; the maximum was $€ 1,700,000$, and the average was $€ 400,000$.

- Your firm capital is $€ 2,400,000$. This is above average and enough to finance innovation. In case of the maximal loss of $€ 800,000$ your enterprise can continue to exist for the coming years.

Based on these factors you can tick which option you prefer. You may only tick one option.

You can consider the scenario's to be independent from each other, there is no sequence!

Fig. 5. Sample question with explanation. 
The vignette was framed in such a manner that, congruently with study 1 , the expected results from investing in innovation were equal to the expected results of remaining inert. The only difference was the uncertainty in the outcome. After the vignette, the questionnaire contained a sample choice task with attribute levels specified. It was explained how the respondent should read the choice task (see Fig. 5). From the vignette and the choice task it can be seen that the choice dilemma is similar to the experiment of study 1 , but that the context has changed to entrepreneurial decision making.

The DCE originally used an $8 \times 8 \times 2$ full factorial design. In total this yielded 128 tasks. These were systematically distributed over eight different versions of the questionnaire, with each questionnaire version containing sixteen tasks for the respondents to fill-in.

Categories for recent experience ranged from - $€ 800,000$ to $€ 1,600,000$ with $€ 400,000$ increments. Furthermore, a special category was added for no previous investment in innovation and at $-€ 400,000$.

Economic status had categories ranging from $€ 800,000$ to $€ 3,600,000$ with $€ 400,000$ increments. However, during data collection, a pre-analysis revealed that respondents did not show any innovative behavior as a result of lack of resources, since no investment leads to sure bankruptcy. Therefore in the last round of data collection the questionnaire was expanded with two extra choice tasks in each version. These tasks contained a "near death" category of economic status. Firm capital was down to $€ 600,000$. Respondents could get a loan from a venture capitalist of $€ 200,000$ to invest in innovation. At the end of the year, the company had to pay back the loan plus $€ 50,000$ interest. In the case of a firm with capital worth less than $€ 250,000$ at the end of the year, the enterprise would go bankrupt; meaning it had to pay off as much debt as possible and then cease to exist. Because of the $€ 50,000$ interest, the expected results of innovation in this scenario are actually lower than in the other scenarios. To keep the full factorial intact, all levels of recent experience were equally distributed over these new choice tasks.

Environmental change had two levels; a stable environment was described as:

"The market in which you are active is very stable; there is little change over the years, which makes the market very predictable."

A variable environment was described as:

"The market in which you are active is very dynamic; there is continuous change and much uncertainty. It is therefore impossible to predict what will happen in the future."

In each questionnaire the level of environmental change was kept constant but the levels of recent experience and economic status varied systematically. Because of the full factorial design there was no correlation between the independent variables.

Additionally, the questionnaire measured global innovativeness using the same adapted translated scale as in study 1 . The Chronbach's Alpha was 0.79 , which is satisfactory.

\subsubsection{Analysis}

To test our hypotheses, a mixed-logit model was fitted using the R-program (R Development Core Team, 2010) and the lme4 package (Bates and Sarkar, 2006). The attributes and global innovativeness were used as predictors. Analogous to study 1 , different models were specified. The first model contained interaction terms of recent experience and economic status with environmental change. The next three models analyzed each condition separately. In a pre-analysis, recent experience and economic status were modeled as nominal variables. These results indicated that the effects of recent experience approximate a linear relationship. To save degrees of freedom and to ease interpretation, it was therefore modeled as a linear continuous variable. Having invested in innovation on a previous occasion was included as dummy variable. Economic status remained a nominal variable because the relationship with the dependent variable was non-linear. This model specification does not influence our results but eases presentation and interpretation. Further, the effects of gender, age and course participation were tested but did not yield any significant results. To save degrees of freedom and prevent confounding effects, they were excluded from the model.

\subsubsection{Results and discussion}

Table 4 displays the results of the mixed-logit models that predict stated investments in innovation.

Model 1 reveals that respondents confronted with a variable environment are less likely to innovate than those in a stable environment. This effect is relatively small but significant at the $10 \%$ level. In this stated choice experiment, respondents prefer the opportunity and certainty provided by the stable environment to invest in innovation over the pressure to innovate in the variable condition. Further, there are moderating effects of environmental condition by recent experience and global innovativeness, both significant at the $10 \%$ level; no such effect exists for economic status.

Model 2 shows that in the stable condition, there is a positive effect of recent experience on innovation, which is in line with Hypothesis 1. Model 3 shows that in the variable condition, the same effect exists (supporting Hypothesis 2). However, the negative interaction effect (at the 10\%) with condition in model 1 signifies that it is somewhat smaller than in the stable condition, which is in line with Hypothesis $2 b$. Since this study was only an exercise on paper, we cannot say anything about the type of routines that were developed.

An interesting observation is the negative effect of previous innovation. Respondents who have had no signal from recent experience (because there was no investment) are more likely to innovate than those who suffered the same loss of $€ 400,000$ on the previous occasion after they did invest. This finding is consistent with prospect theory, which states that people are more risk seeking in situations that involve sure losses (Kahneman and Tversky, 1979). It is difficult to draw any conclusion from this observation, since the previous innovation option is nested in the $-€ 400,000$ category of recent experience. No inferences can be made beyond this category.

Economic status is significant both in model 2 and 3, with no difference between the two conditions. It can be seen that lower categories of economic status have a significantly lower estimator than the extra "near death" category. This result implies that in case of near death of their enterprise, respondents are more likely to invest in innovation; necessity can thus be the mother of invention. The size of the estimators is monotonically increasing over the categories of economic status ranging from $€ 800,000$ to $€ 3,200,000$. In both conditions, the likelihood of innovation appears to be lower for the $€ 3,600,000$ category than for the $€ 3,200,000$ category. No statistical difference between these estimators was observed in the stable condition $(p=0.26)$, but the estimators were different in the variable condition $(p<0.01) .^{7}$ This means that Hypothesis 3 is supported; there is a U-shaped relationship between economic status and innovation in the stable condition.

In the variable condition, the effect of economic status appears to be much less consistent. A chi-square test revealed that this

\footnotetext{
7 The difference was tested by estimating separate models for both conditions with equality constraints imposed upon the estimators of the two categories. Next, model likelihoods were compared with the original model using a chi-square test with $\mathrm{df}=1$.
} 
Table 4

The results of the random-effect logistic regression models.

\begin{tabular}{|c|c|c|c|}
\hline Variable & Model 1 - innovation total & Model 2 - stable & Model 3 - variable \\
\hline Intercept & $2.618^{*}$ & $2.633^{*}$ & -1.559 \\
\hline Variance random intercept & 0.913 & 0.985 & 0.847 \\
\hline Recent experience & $1.544^{* * *}$ & $1.555^{* * *}$ & $1.153^{* * *}$ \\
\hline Previous innovation & $-1.694^{* * *}$ & $-1.703^{* * *}$ & $-0.874^{* * *}$ \\
\hline Economic status: $€ 600,000+$ loan, "near death" (reference category) & 0 & 0 & 0 \\
\hline Economic status: $€ 800,000$ & $-2.096^{* * *}$ & $-2.116^{* *}$ & $-1.413^{* *}$ \\
\hline Economic status: $€ 1,200,000$ & $-1.056^{*}$ & $-1.069^{*}$ & -0.496 \\
\hline Economic status: $€ 1,600,000$ & -0.302 & -0.310 & -0.253 \\
\hline Economic status: $€ 2,000,000$ & 0.624 & 0.623 & 0.547 \\
\hline Economic status: $€ 2,400,000$ & $1.725^{* *}$ & $1.732^{* *}$ & $2.090^{* * *}$ \\
\hline Economic status: $€ 2,800,000$ & $2.047^{* * *}$ & $2.053^{* * *}$ & $1.428^{* *}$ \\
\hline Economic status: $€ 3,200,000$ & $3.001^{* * *}$ & $3.012^{* * *}$ & $3.922^{* * *}$ \\
\hline Economic status: $€ 3,600,000$ & $2.191^{* * *}$ & $2.197^{* * *}$ & $1.609^{* *}$ \\
\hline Global innovativeness & -0.006 & -0.005 & $0.029^{* *}$ \\
\hline Environmental change $($ stable $=1$, variable $=2$ ) & $-4.187^{*}$ & & \\
\hline Recent experience $\times$ environmental change & $-0.385^{*}$ & & \\
\hline Innovation in previous round $\times$ environmental change & $0.815^{*}$ & & \\
\hline Economic status: $€ 800,000 \times$ environmental change & 0.676 & & \\
\hline Economic status: $€ 1,200,000 \times$ environmental change & 0.557 & & \\
\hline Economic status: $€ 1,600,000 \times$ environmental change & 0.046 & & \\
\hline Economic status: $€ 2,000,000 \times$ environmental change & -0.069 & & \\
\hline Economic status: $€ 2,400,000 \times$ environmental change & 0.381 & & \\
\hline Economic status: $€ 2,800,000 \times$ environmental change & -0.614 & & \\
\hline Economic status: $€ 3,200,000 \times$ environmental change & 0.941 & & \\
\hline Economic status: $€ 3,600,000 \times$ environmental change & -0.576 & & \\
\hline Global innovativeness $\times$ environmental change & $0.034^{*}$ & & \\
\hline Number of observations & 1698 & 818 & 880 \\
\hline$N$ & 104 & 50 & 54 \\
\hline Log likelihood & -680.00 & -310.6 & -369.10 \\
\hline
\end{tabular}

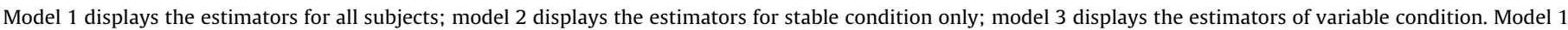
contains four interaction effects between the condition and the confounding effects to see whether there are differences between both.

${ }^{*} p<0.1$.

** $p<0.05$

*** $p<0.01$.

relationship is better described by a cubic relationship than a linear $(p<0.01)$ or quadratic one $(p<0.01)$. The results thus indicate that in a variable condition low-status respondents that are "near death" are more likely to innovate, than those that are not near bankruptcy. In general, high-status individuals are more innovative than low-status individuals but those with the highest status are less likely to innovate than the next highest category. A possible explanation could be that respondents felt sufficiently protected from bankruptcy that there was no need to risk valuable resources (see Cancian, 1967). Another possible explanation is that respondents were already on top of the status hierarchy and therefore felt no need to take any further risks that could endanger their position. On the other hand, those in the second highest category could have used the highest category as a reference group (Massini et al., 2005), and aspired to rise further in the hierarchy of resources to the top category. For our hypotheses, the result resembles 4a best, but the relationship is more complicated than anticipated.

Finally, consistent with Hypothesis 5, global innovativeness is positively related to innovation in the variable condition, but not in the stable condition.

\section{Conclusions and discussion}

\subsection{Conclusions}

This paper studied the following research question: "To what extent does environmental change influence the relationship between recent experience, economic status and innovative behavior?" We presented the results of two empirical studies: one in the form of a behavioral experiment in the controlled setting of a laboratory and the other in the form of a discrete choice experiment (DCE) to measure stated behavior in a more realistic context. The main purpose of our empirical studies was to obtain internal validation of our theoretical model. However, it should be noted that we did not measure innovative behavior in a real world context, our findings are thus indicative of what is expected to happen. The results of these experimental studies need to be triangulated with results from other studies (Colquitt, 2008).

Our theory implied that there is a difference in the origins of innovative behavior. In the behavioral study 1 , we were better able to distinguish between ad hoc problem solving and the development of dynamic capabilities than in study 2 which measured only stated choices. Study 2, on the other hand, took place in a more realistic context. The two studies complement each other by compensating for each other's weaknesses. Despite the differences in approach, the results of both studies are remarkably consistent.

Although recent experience is not always a correct guideline; it turned out to be a guide for future behavior in both conditions, though this relationship was moderated by environmental change in study 2 . This finding confirms the signaling value of recent experience: respondents seem to look at how well they have been doing, given environmental conditions.

The U-shaped relationship between economic status and innovative behavior was supported in both studies, though in study 2 this was caused by the inclusion of a "near death" category (that was actually less attractive for innovation than the other categories).

No relationship was found for economic status in the variable condition of study 1 , while this relationship resembled a cubic relationship in study 2 . Theoretically, we were also unable to predict what this relationship would look like. Both studies seem to point to the positive relationship predicted by Hypothesis 4a but, given the contradicting results from both studies and the lack of sound 
theoretical underpinning, we cannot draw any conclusions about this relationship.

Finally, the results were consistent regarding the effects from global innovativeness. When the position of the innovation boundary is more uncertain, global innovativeness is positively related to innovative behavior.

\subsection{Discussion and future research}

Our model is an extension of existing models that predict innovative behavior (mainly Slevin, 1971). We added the role of environmental change in interaction with economic status and recent experience to the model and tested this in a controlled experimental setting. There are some points of discussion and avenues for further research.

First, both studies employed students (familiar with innovation) as subjects. Though our theory is written from a universal perspective, the question remains to what extent the results can be generalized to the context of entrepreneurs and organizations. Given the background of the respondents and the context-specificity of study 2 , we argue that the findings could be transferable to the entrepreneurship context. However, we stated earlier that the transferability of our results to the organizational level depends on the complexity of the organization to which the result is to be transferred. We agree with Stevens (2011) that sampling should be irrelevant for universal theories, but we also believe that for each theory this should be tested extensively. Future research should apply DCEs to entrepreneurs, organizations or individuals at various positions in organizations to gain further confirmation of the model. In the research on organizations, case complexity should be modeled as a separate factor or as covariate.

Second, the measure of innovative behavior in study 1 was to explore an unknown situation. Whether or not this is a valid measure for innovative behavior is debatable. In our theory, it has already been stated that there are many forms of innovative behavior (see discussion above). The dominant characteristic of all these types of innovative behavior is risk taking and novelty (Benner and Tushman, 2002). This was also the main difference between innovating and not innovating in our study. Further, in study 2 , the measure of innovative behavior was transferred to an explicit business context. Both studies gave similar results that are in accordance with theory. Therefore, we believe that our measure has captured innovative behavior sufficiently in our research context, though there is a strong emphasis on risk-taking. However, for generalization to a real-life context, it is important to tailor the measure to the specific situation. Clearly this level of detail was not employed in our studies. Future research needs to take this into account when validating our results in a real world context.

Third, in study 2, we added a "near death" category, which included a loan. We know that the decision to invest in innovation was objectively less attractive than remaining inert for this category. However, we do not know what the effect of loans is on the model. The principle of loans might have affected the likelihood of innovation. Without the "near death" category, the relationship between status and innovation in the stable condition of study 2 would have been a linear one. The current results match our theory, but the effect of loans is something that future research should look into.

Fourth, as a baseline, we have chosen to set the cost-benefit ratio to be the same for innovation and non-innovation. We also did not include the magnitude of environmental change in the current studies as a separate dimension. These parameters could also be varied in future research, for example, by explicitly including the costs of innovation or quantifying environmental change. DCEs provide an especially feasible opportunity to do so.
Finally, we have presented two experimental examples that gave consistent results, providing internal validity to contemporary theory (Colquitt, 2008). We thereby responded to the call by Sørensen et al. (2010), to apply the experimental method in innovation research. We hope that others will do so too. It should be noted, however, that these methods complement other research methods, such as qualitative case studies or surveys. Where experiments score highest on internal validity, they can be perceived as artificial, ignoring context, and being difficult to generalize. Qualitative case studies are particularly well suited to grasp context, while surveys are useful for generalization (Bryman, 2008). In order to fully understand innovation it is necessary to use all three types of research methods.

\section{References}

Ackerman, P.L., 1988. Determinants of individual differences during skill acquisition: cognitive abilities and information processing. Journal of Experimental Psychology 117, 288-318.

Ambrosini, V., Bowman, C., Collier, N., 2009. Dynamic capabilities: an exploration of how firms renew their resource base. British Journal of Management 20, S9-S24.

Bandura, A., 1977. Social Learning Theory. Prentice Hall, Englewood Cliffs, NJ.

Barnett, W.P., Hansen, M.T., 1996. The red queen in organizational evolution. Strategic Management Journal 17, 139-157.

Barney, J., 1991. Firm Resources and Sustained Competitive Advantage. Journal of Management 17, 99-120.

Bates, D., Sarkar, D., 2006. Ime4: linear mixed-effects models using S4 classes, pp. R package version 0.995-992.

Batsell, R., Louviere, J., 1991. Experimental analysis of choice. Marketing Letters 2, 199-214.

Becker, M.C., 2004. Organizational routines: a review of the literature. Industrial and Corporate Change 13, 643-677.

Benner, M.J., Tushman, M., 2002. Process management and technological innovation: a longitudinal study of the photography and paint industries. Administrative Science Quarterly 47, 676-706.

Betsch, T., Fiedler, K., Brinkmann, J., 1998. Behavioral routines in decision making: the effects of novelty in task presentation and time pressure on routine maintenance and deviation. European Journal of Social Psychology 28, 861-878.

Betsch, T., Haberstroh, S., Glockner, A., Haar, T., Fiedler, K., 2001. The effects of routine strength on adaptation and information search in recurrent decision making. Organizational Behavior and Human Decision Processes 84, 23-53.

Betsch, T., Haberstroh, S., Molter, B., Glockner, A., 2004. Oops, I did it again - relapse errors in routinized decision making. Organizational Behavior and Human Decision Processes 93, 62-74.

Bloom, M., Milkovich, G.T., 1998. Relationships among risk, incentive pay, and organizational performance. Academy of Management Journal 41, 283-297.

Bolton, M.K., 1993. Organizational innovation and substandard performance - when is necessity the mother of innovation. Organization Science 4, 57-75.

Bower, G.H., Hilgard, E.R., 1981. Theories of Learning, 5th ed. Prentice-Hall Inc., Englewood Cliffs.

Boyd, R., Richerson, P.J., 1985. Culture and the Evolutionary Process. The University of Chicago Press, Chicago.

Broder, A., Schiffer, S., 2006. Adaptive flexibility and maladaptive routines in selecting fast and frugal decision strategies. Journal of Experimental Psychology: Learning Memory and Cognition 32, 904-918.

Bryman, A., 2008. Social Research Methods, 3rd ed. Oxford University Press, Oxford

Campbell, D.T., Stanley, J.C., 1966. Experimental and Quasi-Experimental Designs for Research. Houghton Mifflin Company, London.

Cancian, F., 1967. Stratification and risk-taking: theory tested on agricultural innovation. American Sociological Review 32, 912-927.

Cancian, F., 1976. Reply to Morrison, Kumar, Rogers and Fliegel. American Sociological Review 41, 919-923.

Cancian, F., 1979. The Innovator's Situation: Upper-Middle-Class Conservatism in Agricultural Communities. Stanfors University Press, Stanford, CA.

Cheng, J.L.C., Kesner, I.F., 1997. Organizational slack and response to environmental shifts: the impact of resource allocation patterns. Journal of Management 23 , 1-18.

Cohen, M.D., Bacdayan, P., 1994. Organizational routines are stored as procedural memory - evidence from a laboratory study. Organization Science 5, 554-568.

Colquitt, J.A., 2008. From the editors: publishing laboratory research in AMJ - a question of when, not if. Academy of Management Journal 51, 616-620.

Cyert, R.M., March, J.G., 1963. A Behavioral Theory of the Firm. Prentice-Hall, Englewood Cliffs, NJ.

Damanpour, F., Gopalakrishnan, S., 1998. Theories of organizational structure and innovation adoption: the role of environmental change. Journal of Engineering and Technology Management 15, 1-24.

Edquist, C., 1997. Systems of innovation approaches - their emergence and characteristics. In: Edquist, C. (Ed.), Systems of Innovation. Pinter, London.

Eisenhardt, K.M., Martin, J.A., 2000. Dynamic capabilities: what are they? Strategic Management Journal 21, 1105-1121. 
Feldman, M.S., 2000. Organizational routines as a source of continuous change. Organization Science 11, 611-629.

Foxall, G.R., Payne, A.F., Walters, D.A., 1992. Adaptive-innovative cognitive styles of Australian managers. Australian Psychologist 27, 118-122.

Gartrell, J.W., 1977. Status, inequality and innovation: the green revolution in Andrah Pradesh, India. American Sociological Review 44, 73-94.

Gavetti, G., Levinthal, D., 2000. Looking forward and looking backward: cognitive and experiential search. Administrative Science Quarterly 45, 113-137.

Giacquinta, J.B., 1975. Status, risk, and receptivity to innovations in complex organizations: a study of the responses of four groups of educators to the proposed introduction of sex education in elementary school. Sociology in Education 48, 38-58.

Greve, H.R., 1998. Performance, aspirations, and risky organizational change. Administrative Science Quarterly 43, 58-86.

Greve, H.R., 2003. Organizational Learning from Performance Feedback - A Behavioral Perspective on Innovation and Change. Cambridge University Press, Cambridge.

Hannan, M.T., Freeman, J., 1984. Structural inertia and organisational change. American Sociological Review 49, 149-164.

Hannan, M.T., Freeman, J., 1989. Organizational Ecology. Harvard University Press, Cambridge, MA.

Hensher, D.A., Rose, J.D., Greene, W.H., 2005. Applied Choice Analysis: A Primer. Cambridge University Press, Cambridge.

Homans, G.C., 1974. Social Behaviour: Its Elementary Forms, Revised ed. Harcourt Brace Jovanovich, Inc., New York.

Houston, J.M., McNamara, J., 1981. How to maximize reward rate on two variable interval paradigms. Journal of Experimental Animal Behaviour 35, 367-396.

Hutchins, E., 1991. Organizing work by adaptation. Organization Science 2, 14-39.

Im, S., Bayus, B.L., Mason, C.H., 2003. An empirical study of innate consumer innovativeness, personal characteristics, and new-product adoption behavior. Journal of the Academy of Marketing Science 31, 61-73.

Kahneman, D., Tversky, A., 1979. Prospect theory: an analysis of decision under risk. Econometrica 47, 263-291.

Kaplan, S., Henderson, R., 2005. Inertia and incentives: bridging organizational economics and organizational theory. Organization Science 16, 509-521.

Kirton, M.J., 1976. Adaptors and innovators: a description and measure. Journal of Applied Psychology 61, 622-629.

Kirton, M.J., 1994. A theory of cognitive style. In: Kirton, M.J. (Ed.), Adopters and Innovators: Styles of Creativity and Problem Solving. , Revised ed. Routledge, London.

Klemperer, P., 1987. Markets with consumer switching costs. Quarterly Journal of Economics 102, 375-394.

Kruglanski, A.W., 1975. The human subject in the psychology experiment: fact and artifact. In: Leonard, B. (Ed.), Advances in Experimental Social Psychology. Academic Press, pp. 101-147.

Laland, K.N., Reader, S.M., 1999. Foraging innovation in the guppy. Animal Behaviour $57,331-340$.

Lant, T.K., 1992. Aspiration level adaptation - an empirical exploration. Management Science 38, 623-644.

Lant, T.K., Montgomery, D.B., 1987. Learning from strategic success and failure. Journal of Business Research 15, 503-517.

Laursen, K., Salter, A., 2006. Open for innovation: the role of openness in explaining innovation performance among UK manufacturing firms. Strategic Management Journal 27, 131-150.

Lave, C.A., March, J.G., 1993. An Introduction to Models in the Social Sciences, 2nd ed. University Press of America, Inc., London.

Levins, R., 1968. Evolution in Changing Environments: Some Theoretical Explorations (MPB-2)(Monographs in Population Biology). Princeton University Press.

Levitt, B., March, J.G., 1988. Organizational learning. Annual Review of Sociology 14, 319-340.

Lieberman, M.B., Montgomery, D.B., 1988. 1St-Mover advantages. Strategic Management Journal 9, 41-58.

Louviere, J., Flynn, T., Carson, R., 2010. Discrete choice experiments are not conjoint analysis. Journal of Choice Modeling 3, 57-72.

Louviere, J.J., Woodworth, G., 1983. Design and analysis of simulated consumer choice or allocation experiments: an approach based on aggregate data. Journal of Marketing Research 20, 350-367.

Manski, C.F., 1977. The structure of random utility models. Theory and Decision 8, 229-254.

Marcati, A., Guido, G., Peluso, A.M., 2008. The role of SME entrepreneurs' innovativeness and personality in the adoption of innovations. Research Policy 37, 1579-1590.

March, J.G., 1988. Variable risk preferences and adaptive aspirations. Journal of Economic Behavior \& Organization 9, 5-24.
March, J.G., 1991. Exploration an exploitation in organisational learning. Organization Science 2, 71-87.

March, J.G., 1994. A Primer on Decision Making: How Decisions Happen. Free Press, New York, NY, Toronto.

Massini, S., Lewin, A.Y., Greve, H.R., 2005. Innovators and imitators: organizational reference groups and adoption of organizational routines. Research Policy 34, 1550-1569.

Meeus, M.T.H., Oerlemans, L.A.G., 2000. Firm behaviour and innovative performance - an empirical exploration of the selection-adaptation debate. Research Policy 29, 41-58.

Midgley, D.F., Dowling, G.R., 1993. A longitudinal-study of product form innovation - the interaction between predispositions and social messages. Journal of Consumer Research 19, 611-625.

Morrison, D.E., Kumar, K., Rogers, E.M., Fliegel, F.C., 1976. Stratification and risktaking: a further negative replication of Cancian's theory. American Sociological Review 41, 912-919.

Nelson, R.R., Winter, S.G., 1982. An Evolutionary Theory of Economic Change. The Belknap of Harvard University Press, Cambridge, MA

North, D.C., 2005. Understanding the Process of Economic Change. Princeton University Press, Princeton.

Pavitt, K., 1984. Sectoral patterns of technical change: towards a taxonomy and a theory. Research Policy 13, 343-373.

Pfeffer, J., Salancik, G., 2003. The External Control of Organizations: A Resource Dependence Perspective. Stanford Business Books.

Podsakoff, P.M., MacKenzie, S.B., Lee, J.Y., Podsakoff, N.P., 2003. Common method biases in behavioral research: a critical review of the literature and recommended remedies. Journal of Applied Psychology 88, 879-903.

R Development Core Team, 2010. R: A Language and Environment for Statistical Computing. R Foundation for Statistical Computing, Vienna.

Raelin, J.A., 1997. A model of work-based learning. Organization Science 8, 563-578.

Reader, S.M., Laland, K.N., 2001. Primate innovation: sex, age and social rank differences. International Journal of Primatology 22, 787-805.

Reader, S.M., Laland, K.N., 2003. Animal innovation: an introduction. In: Reader, S.M., Laland, K.N. (Eds.), Animal Innovation. Oxford University Press, Oxford.

Rogers, E.M., 1995. Diffusion of Innovations, 4th ed. Free Press, New York.

Rogers, E.M., 2003. Diffusion of Innovations, 5th ed. Free Press, New York.

Rosenkopf, L., McGrath, P., 2011. Advancing the conceptualization and operationalization of novelty in organizational research. Organization Science 22, 1297-1311.

Scott, W.R., 1995. Institutions and Organizations. SAGE, Thousand Oaks.

Sitkin, S.B., Pablo, A.L., 1992. Reconceptualizing the determinants of risk behavior. Academy of Management Review 17, 9-38.

Slevin, D.P., 1971. The innovation boundary: a specific model and some empirical results. Administrative Science Quarterly 16, 515-532.

Sørensen, F., Mattsson, J., Sundbo, J., 2010. Experimental methods in innovation research. Research Policy 39, 313-322.

Sørensen, J.B., Stuart, T.E., 2000. Aging, obsolescence, and organizational innovation. Administrative Science Quarterly 45, 81-112.

Stevens, C.K., 2011. Questions to consider when selecting student samples. Journal of Supply Chain Management 47, 19-21.

Suarez, F.F., Lanzolla, G., 2007. The role of environmental dynamics in building a first mover advantage theory. Academy of Management Review 32, 377-392.

Sutcliffe, K.M., Zaheer, A., 1998. Uncertainty in the transaction environment: an empirical test. Strategic Management Journal 19, 1-23.

Tidd, J., Bessant, J., Pavitt, K., 2001. Managing Innovation: Integrating Technological, Market and Organizational Change. John Wiley \& Sons, Chichester.

Van de Ven, A.H., Polley, D., 1992. Learning while innovating. Organization Science 3, 92-116.

Van Rijnsoever, F.J., Donders, A.R.T., 2009. The effect of innovativeness on different levels of technology adoption. Journal of the American Society for Information Science and Technology 60, 984-996.

Van Rijnsoever, F.J., Hessels, L.K., 2011. Factors associated with disciplinary and interdisciplinary research collaboration. Research Policy 40, 463-472.

Van Rijnsoever, F.J., Hessels, L.K., Vandeberg, R.L.J., 2008. A resource-based view on the interactions of university researchers. Research Policy 37, 1255-1266.

Van Rijnsoever, F.J., Oppewal, H., 2012. Predicting early adoption of successive video player generations. Technological Forecasting and Social Change 79, 558-569.

Vishwanath, A., 2005. Impact of personality on technology adoption: an empirical model. Journal of the American Society for Information Science and Technology $56,803-811$.

Winter, S.G., 2003. Understanding dynamic capabilities. Strategic Management Journal 24, 991-995.

Zollo, M., Winter, S.G., 2002. Deliberate learning and the evolution of dynamic capabilities. Organization Science 13, 339-351. 